\title{
Analysis of Painted Materials and the Latest Repaint Time of Arhat Statues in Zijin Nunnery, China
}

\author{
Qiang Cui ${ }^{1, *}$, Biwen Shui ${ }^{1}$, Fasi Wu ${ }^{1}$, Qianli Fu², Xia Feng ${ }^{3}$ \\ ${ }^{1}$ National Research Center for Conservation of Ancient Wall Paintings and Earthen Sites, Department of Conservation Research, \\ Dunhuang Academy, Dunhuang, Gansu, 736200, PR China \\ ${ }^{2}$ Emperor Qin Shihuang's Mausoleum Site Museum, Xi'an, Shaanxi, Jiangsu, 710600, PR China \\ ${ }^{3}$ Suzhou Wuzhong District Zijin Nunnery Scenic Spot Management Office, Suzhou, 215107, PR China \\ *Correspondence author,cq20229@dha.ac.cn; sbw20290@dha.ac.cn;wufs@dha.ac.cn
}

\begin{abstract}
The arhat statues of Zijin Nunnery in Suzhou are painted clay statues considered to be ancient Chinese treasures, but there has been little investigation into the materials used in their manufacture along with a general lack of systematic and scientific knowledge regarding these statues. We attempted to address this deficiency in our study described here, where the materials comprising the pigment layer of the colored statues were characterized using a variety of techniques, including X-ray fluorescence, X-ray diffraction, micro infrared spectroscopy, and micro Raman spectroscopy. A range of contemporary synthetic pigments, such as chrome yellow, emerald green, and artificial ultramarine, was discovered to be available in addition to conventional inorganic pigments such as cinnabar, minium, and azurite. Analysis of the massive statue in the main hall showed that shellac is used as a surface sealing compound on the painted clay statue and beeswax as a bonding medium for the pigment layer. Following an extensive investigation into the synthetic pigments, it was determined that the painted statues of Zijin Nunnery were painted during the most recent era of the late Qing Dynasty.
\end{abstract}

Keywords: Zijin Nunnery, Painted clay statues, Composition detection, Artificial pigment, Cultural treasures conservation.

\section{Introduction}

Ancient painted clay statues and murals are precious cultural relics that have been preserved as human society has evolved. They are extensively distributed in many regions of the globe, including Europe, Asia, and Latin America. They may be found in cathedrals, grottoes, temples, tombs, and other constructs across the world. Moreover, they have prominent historical, aesthetic, scientific, social, and cultural significance. Unfortunately, the outlook for the continued preservation of these cultural treasures is not optimistic owing to the properties of the building materials and construction methods, external environmental factors, and human activities; they face a variety of threats, and some are even already on the verge of disappearance. For example, the Mogao Grottoes in Dunhuang, a World Cultural Heritage Site, face a variety of problems, including paint separation, paint layer disintegration, alkalinity, and discoloration. The scientific examination of the materials used in the manufacture of cultural relics, on the other hand, is the first step toward ensuring their efficient conservation and long-term survival. As a result, a broad range of analytical tools is being extensively used to derive the representative information of cultural heritage assets[1-5].

It is difficult to conserve cultural treasures, such as painted clay statues, since external factors may easily affect the body material. Due to the adverse impact of the humid climate in southern China, there are few remains of the painted clay cultural relics of this region. It has been difficult for the arhat statues in Zijin Nunnery, as a fine specimen of painted clay statues, to survive to this day in their original state. Zijin Nunnery is located in the Wuzhong District of Suzhou City in China's Jiangsu Province. The Liang and Chen periods of the Southern Dynasties saw the establishment of the nunnery, and there are only two halls at present. The sixteen colored arhat statues that have survived on the north and south fronts of the hall were crafted by the great artisan Lei Chao and his wife during the Song Dynasty[6]. The arhat statues feature vibrant forms and a variety of facial expressions. They are a rare artistic treasure in ancient Chinese painted clay statues[7]. In addition, they offer valuable research resources for the study of arhat beliefs as well as the history, culture, sculptural art, social norms, and Buddhism of the Suzhou-Hangzhou region, and their importance was officially recognized by a national essential cultural relics preservation unit in 2006.

In the past, study on the arhat statues in Zijin Nunnery was primarily concerned with the aesthetic and historical significance of the statues, with little attention paid to the materials used in the statues' construction[8]. The arhat statues in the Zijin Nunnery have a history dating back more than 800 years, and the damage to the painted layer is becoming increasingly severe. In addition, there is a dearth of study on the materials used in the crafting processes, which makes it impossible to preserve and restore the statues. As a result, it is vital to conduct scientific studies on the materials used in the painted statues in the Zijin Nunnery in a methodical manner. Thus, we carried out a systematic and thorough examination of the painting materials used on the painted clay statues of Zijin Nunnery using nondestructive investigation and laboratory micro-sample analysis; moreover, the period during which these statues were repainted was also determined.

\section{Materials and Methods}

\subsection{Introduction to the Painted Statues in Zijin Nunnery}

Zijin Nunnery is situated in Xiwu, Dongshan, Taihu Lake, at longitude $120^{\circ} 39^{\prime}$ east and latitude $31^{\circ} 06^{\prime}$ north (Figure 1a). It has a subtropical monsoon oceanic climate, four distinct seasons, and is warm and rainy with obvious monsoons. The average annual temperature is $15.7^{\circ} \mathrm{C}$, and the average annual relative humidity is $76 \%$. Yearly precipitation averages 1063 $\mathrm{mm}$, annual solar radiation totals $4651.1 \mathrm{~J} / \mathrm{m}^{2}$, and annual 
sunshine hours total 1965.0h.

The great hall houses the painted clay statues and is the nunnery's major structure (Figure 1b). There are a total of 59 painted clay statues on display. In total, there are six large statues: the three Trikalea Buddhas (Buddhas of the past, present, and future), Guanyin Bodhisattva, and two disciples, all of which stand around 170 to $180 \mathrm{~cm}$ tall. There are also 24 statues of arhat and other deities, each standing at a height of about $100 \mathrm{~cm}$, and 24 statues of the dharma protector Heavenly God, each standing at a height of about $90 \mathrm{~cm}$ (Figure 1c). The remaining five small statues all stand below $50 \mathrm{~cm}$ in height.

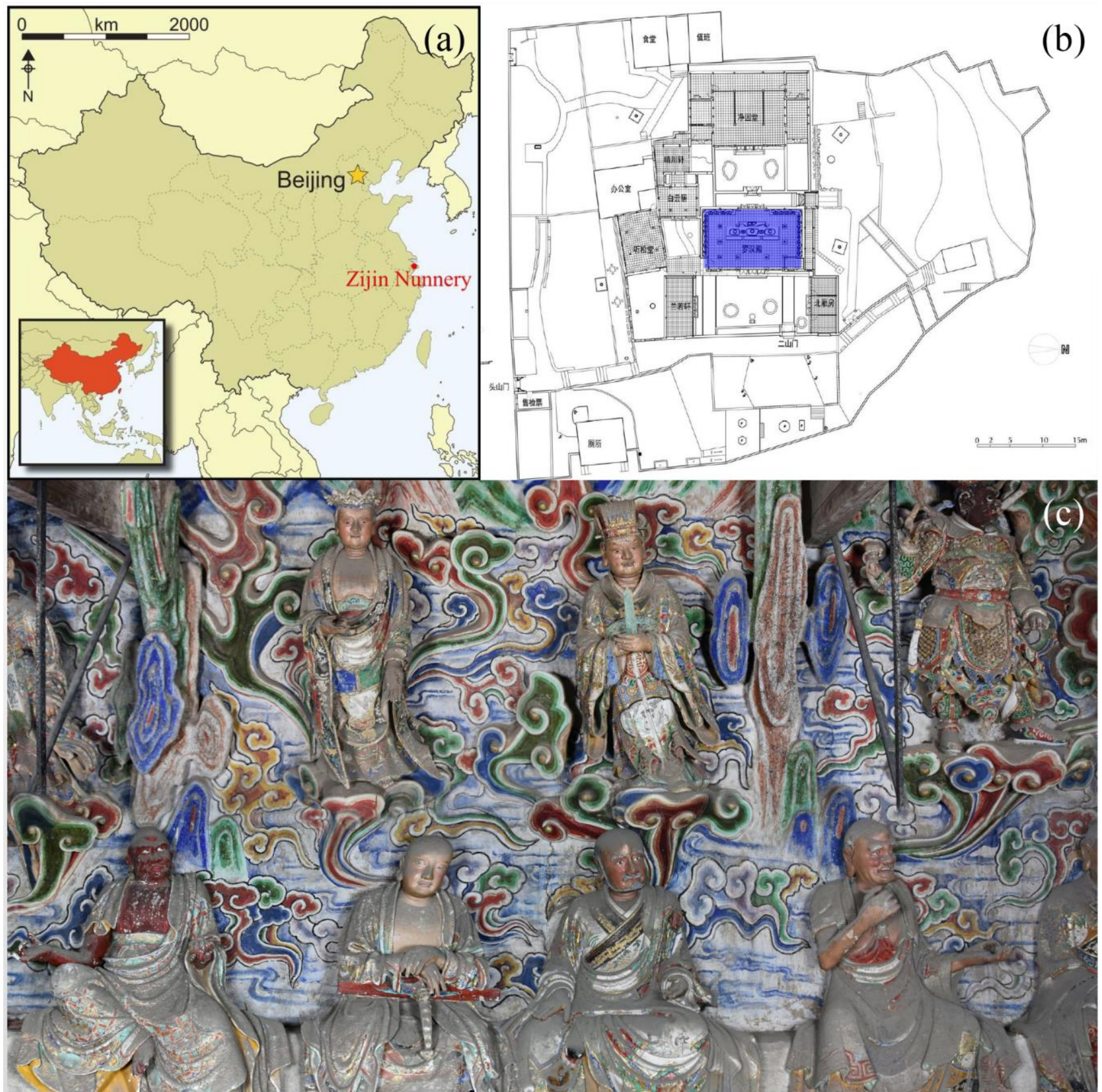

Figure 1: Painted clay statues of Zijin Nunnery in Suzhou and location details: (a) location of Zijin Nunnery in China; (b) architectural layout of Zijin Nunnery, blue part is the main hall where the painted statues are located; (c) photos of painted clay statues in the main hall.

\subsection{Research Objects}

XRF was utilized for in situ nondestructive analysis of 14 statues of arhats and other gods, 2 dharma-guarding gods, and 3 huge statues, with a total of 135 sampling points for the determination of such parameters as the shape and specification, molding age, and spatial layout of the statue. As a result, representative Dragon Subduing arhats (statues from the Song Dynasty, Figure 2a), Guan Yu (statues from the
Ming Dynasty, Figure 2b), and Duhai Guanyin (huge, Figure 2c) that were suitable for the examination were chosen as the research objects for investigation. After obtaining permission from the Zijin Nunnery scenic spot management office, a scalpel was used to sample minor damage to a statue in a damaged or hidden location. The sampling amount was generally no more than $10 \mathrm{mg}$, and it was then returned to the laboratory for analysis and research. Table 1 contains the specifics of the sampling procedure and information. 


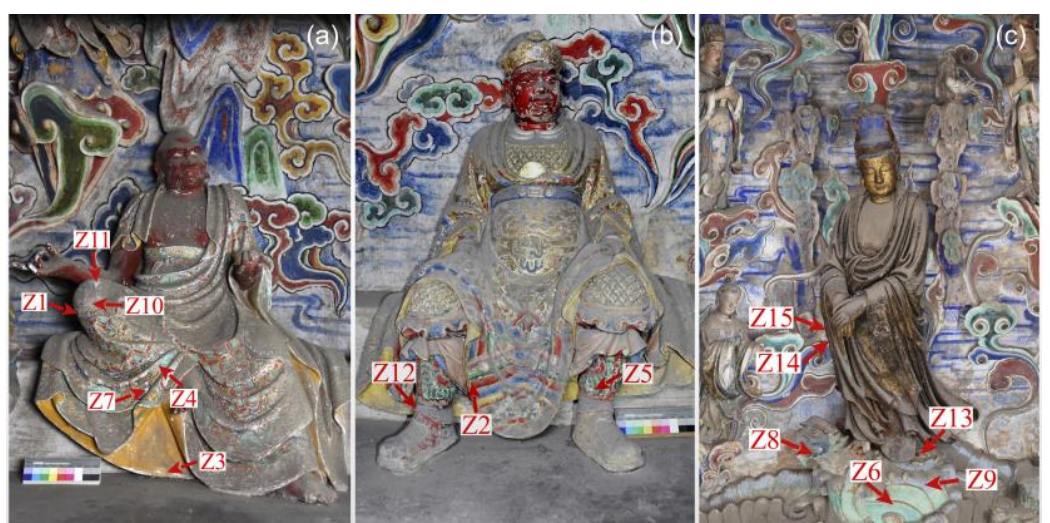

Figure 2: Sampling positions on painted clay statues in Zijin Nunnery: Sampling positions on statues of (a) Dragon subduing arhat, (b) Guan Yu and (c) Guanyin crossing the sea.

Table 1: Sample information of painted statues including sampling location, color and analytical methods

\begin{tabular}{|c|c|c|c|}
\hline No. & Sampling location & Color & Methods \\
\hline Z1 & Dragon subduing arhat's right calf shirt & Red & XRF; XRD \\
\hline Z2 & The pattern of clothes between Guan Yu's legs & Orange & XRF; XRD \\
\hline Z3 & Dragon subduing arhat shirt & Yellow & Green \\
\hline Z4 & The clothes near the right foot of the Dragon subduing arhat & Green & XRF; XRD \\
\hline Z5 & Guan Yu's right calf shirt & Green & XRF; XRD \\
\hline Z6 & The waves at the foot of Guanyin crossing the sea & Blue & XRF; XRD \\
\hline Z7 & The clothes near the right foot of the dragon subduing Arhat & XRF; XRD \\
\hline Z8 & The face of the squid at the foot of Guanyin crossing the sea & Blue & XRF; XRD; Raman \\
\hline Z9 & The waves at the foot of Guanyin crossing the sea & White & XRF; XRD \\
\hline Z10 & Dragon subduing arhat right knee (surficial layer) & White & XRF; XRD \\
\hline Z11 & Dragon subduing arhat right knee (inner layer) & Soil sample & XRD \\
\hline Z12 & The broken part of Guan Yu's right calf & Soil sample & XRD \\
\hline Z13 & The broken left foot of Guanyin crossing the sea & Sealing material & FTIR \\
\hline Z14 & Clothes of Guanyin crossing the sea & Adhesive material & FTIR \\
\hline Z15 & Between the gaps in the clothes of Guanyin crossing the sea & &
\end{tabular}

\subsection{Analysis Methods}

\subsubsection{Element analysis}

For the elemental analysis of the pigment layer on the surface of the painted statues, the XL3t-800 alloy analyzer (NITON, USA) was used, which was equipped with a high-performance micro X-ray tube, a silver target $50 \mathrm{kV} / 40 \mu \mathrm{A}$, Peltier semiconductor refrigeration, a high-resolution Si-PIN X-ray detector (with a resolution of $195 \mathrm{KeV}$ ), a high-performance filter system, and an ASICS DSP4096 pixel multi-channel analyzer. The detection time was $1 \mathrm{~min}$, and soil analysis mode was adopted.

\subsubsection{Pigment Phase and Composition Analysis}

A Japanese-made Rigaku D-max/2500 X-ray diffractometer (XRD) was used for pigment analysis of the painted statues. Continuous scanning of a copper target was performed with an analysis voltage of $40 \mathrm{kV}$ and a current of $100 \mathrm{~mA}$; the scanning range was 50 to $70 \mathrm{o}$ and was filtered by a graphite monochromator.

The Raman technique was utilized for indication of mineral pigments which could not be determined effectively by XRD method, The Raman system was composed with an excitation source, recording spectrometer and a microscopy (Renishaw inVia). A laser with $514 \mathrm{~nm}$ wavelength was used to be the exciting source. The detection range of spectroscopy was fixed between 100 to $3000 \mathrm{~cm}^{-1}$, which the revolution was about $\pm 1 \mathrm{~cm}^{-1}$. Microscopy with $100 \mathrm{X}$ magnification was employed to achieve the micro-area measuring in the painted clay statues. The recording time was fixed as $10 \mathrm{~s}$, then the spectrum was averaged with five accumulation times during our measurements.

\subsubsection{Analysis of Organic Coatings and Adhesive Materials}

For this study, the Nicolet iN10 MX micro infrared imaging spectrometer (Thermo Fisher Scientific) was used for the measurement of organic materials in colored statue pigments. The detector was MCT/A (liquid nitrogen cooling), the resolution was $4 \mathrm{~cm}^{-1}$, and the scanning duration was 64 times (in transmission mode) and 128 times (ATR mode).

\section{Results}

\subsection{The Elemental Composition of Pigments}

A handheld XRF was used to conduct in situ nondestructive testing on the pigments of 19 statues in the hall using various wavelengths of light. The colors consist of six primary hues: red, orange, yellow, green, blue, and white. Researchers discovered that the elemental information represented by the hue of representative cultural artifacts is disproportionately densely packed (Table 2). $\mathrm{Hg}$ is included in the red pigment. Cinnabar is thought to be the color-developing component, the orange pigment is thought to be mostly $\mathrm{Pb}$, minium is thought to be the probable color-developing component, and $\mathrm{Cr}$ may be found in the yellow pigment (Figure 3a). It is hypothesized that the color-developing component is chrome yellow and that the green pigment is mostly composed of $\mathrm{Cu}$, $\mathrm{As}$, and $\mathrm{Pb}$ (Figure 3b), It was not possible to detect the color-developing component temporarily nor to distinguish between two types of blue pigments. The color-developing component is possible azurite composed of $\mathrm{Cu}$ and $\mathrm{Pb}$ 
components. The other simply comprises $\mathrm{Pb}$ elements, and the component responsible for color development is not known. The surficial layer white pigment is mostly composed of $\mathrm{Pb}$ components (Figure 3c), while the inner white pigment is primarily composed of $\mathrm{Ca}$ elements (Figure 3d), with the color-developing component remaining a mystery.

Table 2: Results of XRF analysis on colored statues.

\begin{tabular}{|c|c|c|}
\hline Color & Test results \\
\hline Red & Crossing the river arhat, subduing the dragon arhat, meditation arhat, crossing the sea $\mathrm{Guanyin}$ \\
\hline Orange & Proud arhat, Liang Wudi, contempt arhat, Anan & $\mathrm{Hg}, \mathrm{Pb}$ \\
\hline Yellow & Door-watching arhat, Guan Yu, subduing the dragon arhat, dragon girl \\
\hline Green & Long-brows arhat, Yue Fei, Chou $\mathrm{Si}$ Arhat, Anan \\
\hline Blue & Door-watching arhat, Yue Fei, admiring the arhat, medicine $\mathrm{Buddha}$ \\
\hline White (surficial layer) & Scripture arhats, Maitreya with big belly, arhats for subduing dragons, eight-armed heavens \\
\hline White (inner layer) & Door-watching arhats, despise arhats, sadness arhats, and eight-armed heavens & $\mathrm{Cu}, \mathrm{As}, \mathrm{Pb}$ \\
\hline
\end{tabular}

(a)

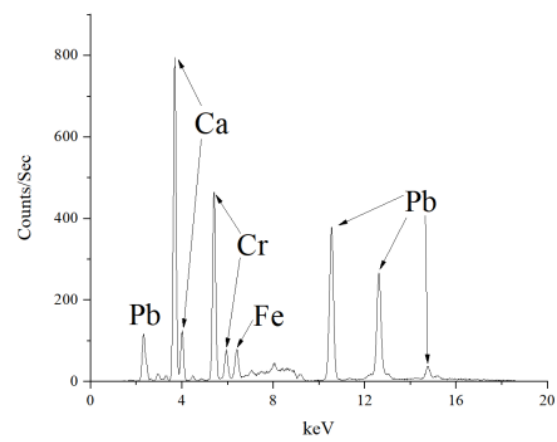

(c)

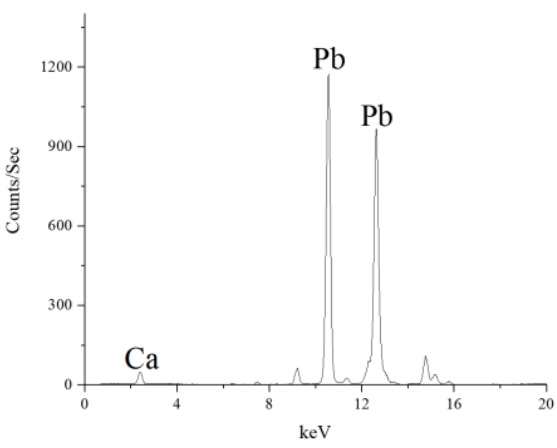

Figure 3: XRF spectra of pigments: (a) yellow; (b) green; (c) white (upper layer); (d) white (lower layer).

\subsection{Mineral Composition of the Pigments}

In order to testify the XRF elemental analysis, the XRD analysis was performed on the trace samples that were acquired at the location and the results was shown in table 3 and Figure 4. In accordance with the data from the table and figure, cinnabar $(\mathrm{HgS})$ is the color-developing component of the red pigment, minium $\left(\mathrm{Pb}_{3} \mathrm{O}_{4}\right)$ is the color-developing component of the orange pigment. Within the green pigment, the coexistence of both mimetite $\left(\mathrm{Pb}_{5}(\mathrm{AsO} 4)_{3} \mathrm{Cl}\right)$ and emerald green $\left(\mathrm{Cu}\left(\mathrm{C}_{2} \mathrm{H}_{3} \mathrm{O}_{2}\right)_{2} \cdot 3 \mathrm{Cu}\left(\mathrm{AsO}_{2}\right)_{2}\right)$ is observed (Figure $4 \mathrm{a}$ ). The use of copper chloride $\left(\mathrm{Cu}_{2}(\mathrm{OH})_{3} \mathrm{Cl}\right)$ was also found.
There are two color-developing components of blue pigment: azurite $\left(\mathrm{Cu}_{3}\left(\mathrm{CO}_{3}\right)_{2}\left(\mathrm{OH}_{2}\right)\right)$ (Figure $\left.4 \mathrm{~b}\right)$ and ultramarine $\left(\mathrm{Na}_{6} \mathrm{Ca}_{2} \mathrm{Al}_{6} \mathrm{Si}_{6} \mathrm{O}_{24}\left(\mathrm{SO}_{4}\right)_{2}\right)$. It is unclear if ultramarine is a naturally occurring or man-made pigment. While hydrocerussite $\left(\mathrm{Pb}_{3}\left(\mathrm{CO}_{3}\right)_{2}(\mathrm{OH})_{2}\right)$ and calcite $\left(\mathrm{CaCO}_{3}\right)$ are the primary constituents of the white pigment in the surficial layer (Figure 4c), calcite dominates in the inner layer, with small quantities of raw gypsum $\left(\mathrm{CaSO}_{4} \cdot 2 \mathrm{H}_{2} \mathrm{O}\right)$ added for good measure (Figure 4d). The yellow pigment and the $\mathrm{Z9}$ blue pigment did not include any color-developing constituents. The above discussion showed that the results of XRF was consist with that of XRD.

Table 3: Results of XRD analysis on colored statues.

\begin{tabular}{|c|c|c|c|}
\hline No. & Color & Test Results & Chromogen \\
\hline Z1 & Red & Calcite, hydrocerussite, cinnabar & Cinnabar \\
\hline Z2 & Orange & Calcite, hydrocerussite, minium & Massicot \\
\hline Z3 & Yellow & Gypsum, calcite, quartz, muscovite & Mimetite \\
\hline Z4 & Green & Mimetite, calcite, gypsum, hydrocerussite, emerald green & Emerald green, arsenic lead \\
\hline Z5 & Green & Calcite, gypsum, atacamite & Atacamite \\
\hline Z6 & Green & Calcite, gypsum, anglesite, hydrocerussite, ultramarine & Altramarine \\
\hline Z7 & Blue & Azurite, calcite, gypsum, quartz & Calcite, gypsum, quartz \\
\hline Z8 & Blue & Quartz, calcite, gypsum, hydrocerussite & Hydrocerussite \\
\hline Z10 & Blue & Calcite, gypsum & Calcite \\
\hline Z11 & White & Quartz, gypsum, muscovite, kaolinite, albite & - \\
\hline Z12 & Soil Sample & Quartz, calcite, gypsum, muscovite & - \\
\hline Z13 & Soil Sample & & \\
\hline
\end{tabular}


(a)

(b)
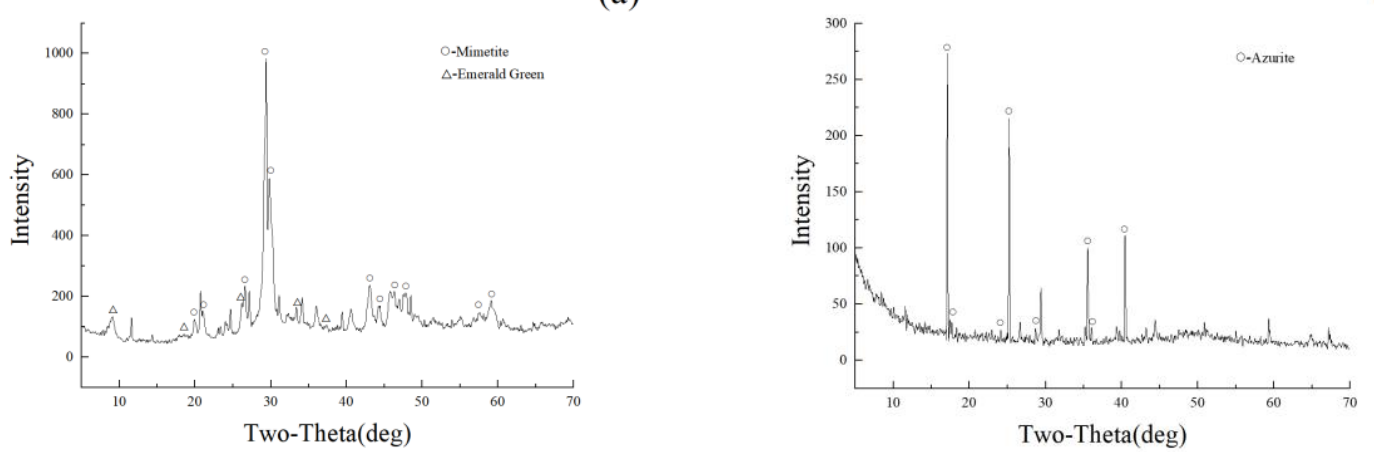

(c)
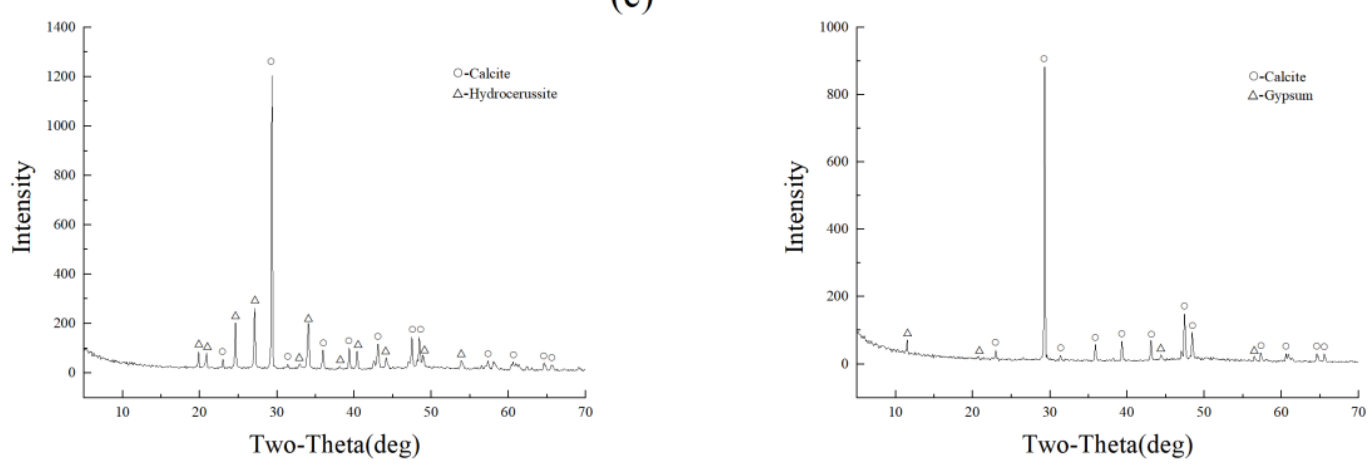

(d)

Figure 4: Partial XRD results of pigments in samples: (a) sample Z5 (emerald green + mimetite); (b) sample Z8 (azurite); (c) sample Z10 (hydrocerussite + calcite); (d) sample Z11 (calcite + gypsum).

Using XRF and XRD analyses, we were still unable to identify the color composition of the $\mathrm{Z} 3$ yellow pigment (Figure 5a) and Z9 (Figure 5c) blue pigment. These samples were subjected to Raman analysis in an attempt to more successfully elucidate the material information. The Raman spectrum of the yellow sample (Figure 5b) has distinctive
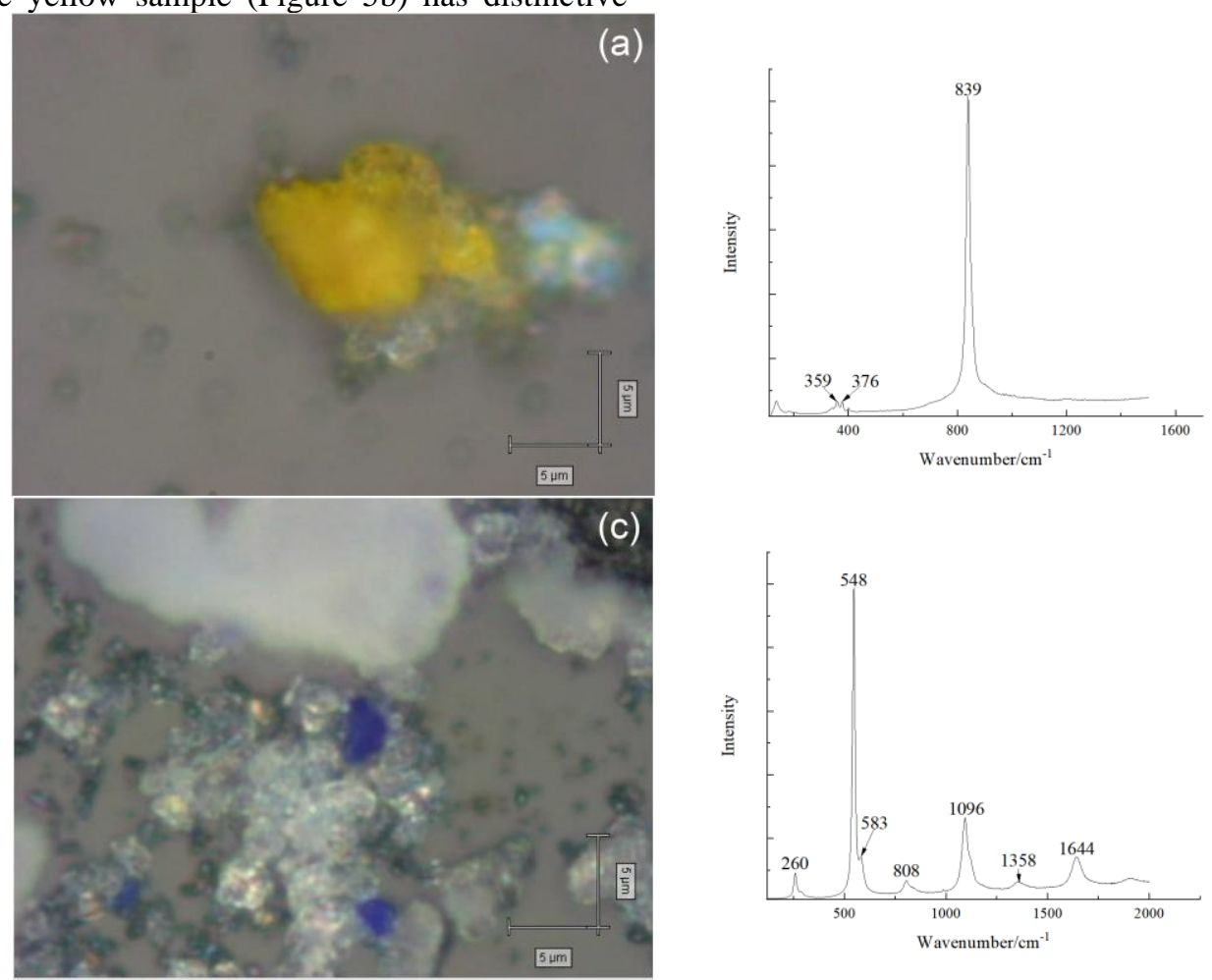

(b) characteristic peaks of crocoite $\left(\mathrm{PbCrO}_{4}\right)[9,10]$. The Raman spectrum of the blue samples contains a number of peaks at 260, 548, 808, 1096, and $1644 \mathrm{~cm}^{-1}$ (Figure 5d), which are essentially characteristic of ultramarine[11].

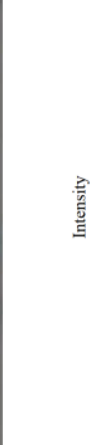

(d)

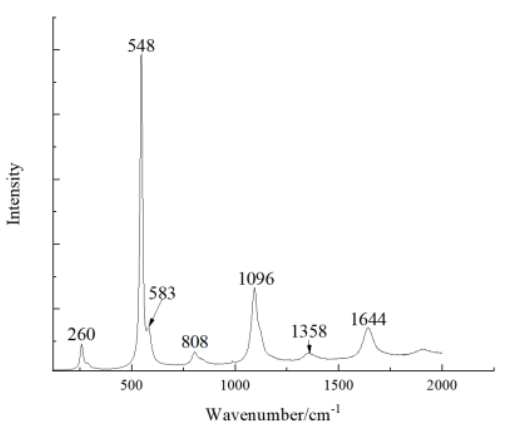

Figure 5: Images and Raman results of pigments: (a) image of Z3 yellow pigment particles and (b) Z3 yellow pigment Raman spectrum; (c) image of Z9 blue pigment particles and (d) Z9 blue pigment Raman spectrum. 


\subsection{Composition of Organic Materials}

In the course of nondestructive testing of painted statues, it was discovered that there is a transparent sealing layer on the surface of the pigment layer, which exhibits a certain amount of reflection when exposed to light. When the break in the pigment layer of the large-scale statue is carefully examined, a milky white paste bonding agent between the matrix and the pigment layer can be seen. In order to determine the differences in composition between the two materials, they were subject to $\mu$-FTIR testing; sample Z14 represents the surface sealing layer (Figure 6a), and sample Z15 represents the paste bonding substance (Figure $6 \mathrm{c}$ ).

he detection results for sample Z14 clearly show absorption peaks at 1144, 1251, 1464, 1716, 2858, 2932, and 3407 $\mathrm{cm}^{-1}$ (Figure 6b), which corresponds to the shellac characteristic peak (shellac) $\left(\mathrm{C}_{15} \mathrm{H}_{20} \mathrm{O}_{6} \cdot \mathrm{C}_{15} \mathrm{H}_{30} \mathrm{O}_{5}\right)$ [12]. There is a large peak around $3407 \mathrm{~cm}^{-1}$ that corresponds to the $\mathrm{O}-\mathrm{H}$ stretching vibration peak, 2932 and $2858 \mathrm{~cm}^{-1}$ have two sharp peaks with high intensity and strong symmetry that correspond to the $\mathrm{C}-\mathrm{H}$ vibration peaks, and the peak at $1716 \mathrm{~cm}^{-1}$ corresponds to

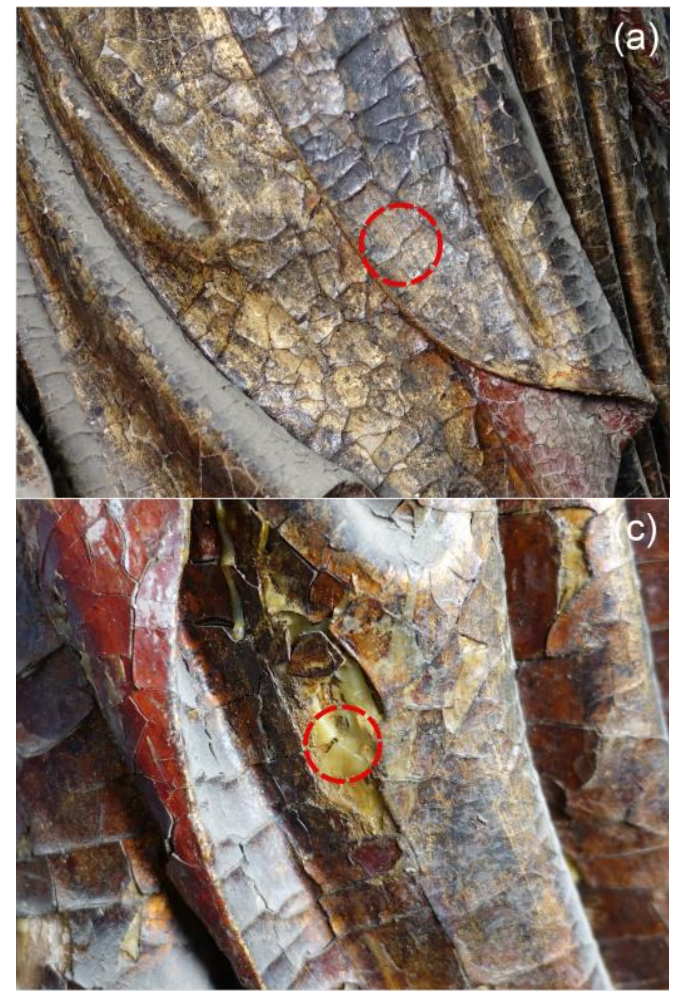

Figure 6: Images and $\mu$-FTIR results of surface sealing layer (Z14) and paste bonding substance (Z15): (a) detailed image of sampling area (encircled in red) and surrounds of sample Z14 and (b) IR spectrum of sample Z14; (c) detailed image of sampling area (encircled in red) and surrounds of sample Z15 and (d) IR spectrum of sample Z15.

\section{Discussion}

Through corroborating and examining the findings of several detection instruments, we have a preliminary understanding of the paint utilized in the arhat statues in Zijin Nunnery. In the following, we proceed to examine the white background color layer craft, emerald green discoloration, artificial ultramarine in color statue, organic materials in painted clay statues, and the rough period of painted statue redrawing.

\subsection{Characteristics of White Background Layer}

The findings of XRF tests on several pigments show that they the carboxyl group. There are four distinct peaks at 1464, 1415,1376 , and $1322 \mathrm{~cm}^{-1}$ that are sharper and correspond to $\mathrm{COO}^{-}$and are generated by the coupling of $\mathrm{O}-\mathrm{H}$ in-plane bending and $\mathrm{C}=\mathrm{O}$ stretching vibrations; there are three distinct peaks at 1251,1144 , and $1114 \mathrm{~cm}^{-1}$ that are relatively sharp and correspond to the $\mathrm{C}=\mathrm{O}-\mathrm{C}$ stretching vibrations of ester molecules[13].

The absorption peaks of sample Z15 can be clearly seen at 720, 1177, 1376, 1464, 1736, 2851, 2921, and 3446 $\mathrm{cm}^{-1}$ (Figure $6 \mathrm{~d})$, which is compatible with the distinctive peak of beeswax $\left(\mathrm{C}_{15} \mathrm{H}_{31} \mathrm{COOC}_{30} \mathrm{H}_{61}\right)$ [14]. Among them, 2921 and $2851 \mathrm{~cm}^{-1}$ are the absorption peaks of the $\mathrm{C}-\mathrm{H}$ stretching vibration in the $-\mathrm{CH} 2$ - group; strong absorption occurs at $1732 \mathrm{~cm}^{-1}$, indicating the presence of ester carbonyl; the $1464 \mathrm{~cm}-1$ peak is due to the in-plane bending vibration absorption of methyl; $1175 \mathrm{~cm}^{-1}$ is the $\mathrm{C}-\mathrm{O}$ stretching vibration absorption peak, which indicates that it is part of a long-chain fatty acid ester; $1019 \mathrm{~cm}^{-1}$ is the antisymmetric stretching vibration of $\mathrm{C}-\mathrm{O}-\mathrm{C}$; and $719 \mathrm{~cm}-1$ is the peak corresponding to in-plane rocking vibration absorption of the $-\mathrm{CH} 2-$ group [15].

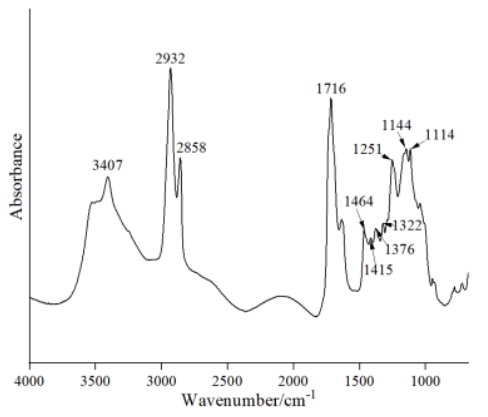

(b)

(d)

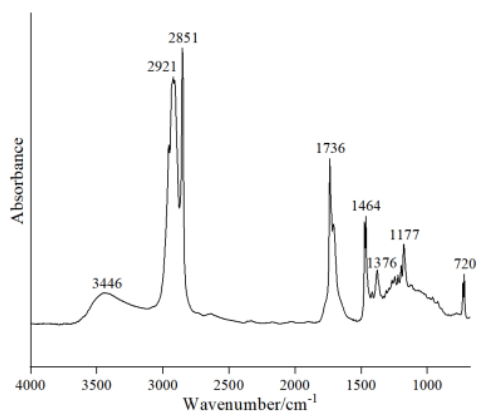

contain lead $(\mathrm{Pb})$. Hydrocerussite is present not just in white pigments but also in pigments of various other colors. As a result, hydrocerussite is thought to be one of the components of the bottom color layer. When the XRF and XRD detection findings for the same region of white pigments in various layers are combined, it can be seen that the surficial layer of white bottom pigment is hydrocerussite and the inner layer is calcite (Figure 7a). In situ nondestructive optical microscopic inspection in the damaged region of white pigment reveals the layer connection of the two pigments (Figure 7b). The material composition was found to be generally singular, and the bottom color usually composed of a single layer. When Zijin Nunnery's color statues were painted, the lowest color 
layer was made up of two layers. On the one hand, this demonstrates the high quality of color painting production. On the other hand, it is possible that two layers were used in Zijin Nunnery because of the humid climate in southern China, and mildew resistance from an additional layer was sought.
According to some researchers, there is virtually no mold in the pigment region containing heavy metal components such as lead and copper in the painting of the Dazu reclining Buddha[16].

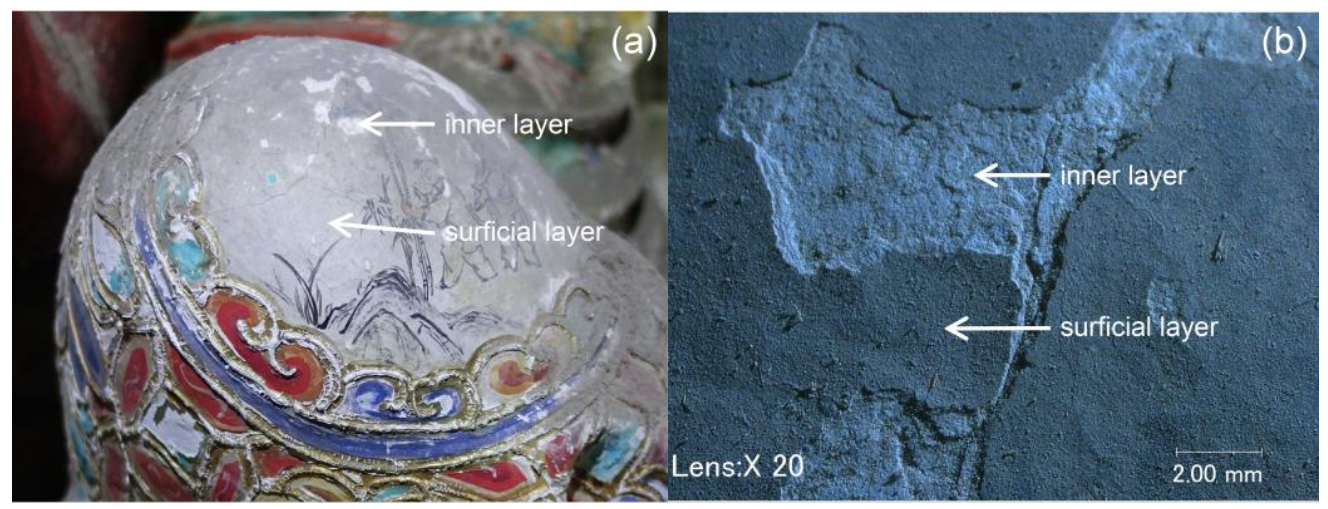

Figure 7: Depth profiling in white areas: (a) white pigment of Dragon subduing arhat's right knee; (b) image from microscopic observation of the white background layer.

\subsection{The Discoloration Phenomenon of Green Pigments}

There are three types of green pigments: mimetite, the coexistence of emerald green and mimetite, and atacamite. Studies have shown that mimetite is a member of the class of pigments with hexagonal crystal structure and that the minerals linked with it are often malachite. Dark green, mild yellow-green, gray-white, and milky white are the most common hues[17,18]. The pigments of the mimetite group that are most often seen are mostly white. Others have studied and analyzed the green pigments of the Xiaofowan statues in the Dazu rock carvings in Chongqing and discovered that the coexistence of emerald green and cerussite will be affected by environmental factors, resulting in the formation of discolored products such as lavendulan and mimetite[19]. Other researchers have employed X-ray powder diffraction imaging methods to determine the process of production of mimetite at the micro and macro scales. This procedure may be broken down into three steps: (1) arsenic (III valence) pigments are oxidized to form arsenate (V valence) after photodegradation under humid and aerobic conditions; (2) arsenate migrates to the lead ion layer (lead ions are degraded from lead white); (3) arsenate, lead ions, and chloride ions react to create mimetite[20].

Zijin Nunnery is located in the southeast of China, which is the subtropical monsoon climate zone. It is hot and humid, with bright sunlight and plenty of rainfall at the same time. The air pollution in the Yangtze River Delta has been worsening in the last 20 years, resulting notably in the issue of acid rain[21]. The white pigment in the painted clay statues in the hall is a blend of calcite and hydrocerussite, the green pigment is emerald green, and the presence of $\mathrm{Cl}^{-1}$ has been found, indicating that the conditions for the formation of mimetite have been met. As a result, mimetite in the green pigment is thought to be the result of emerald green discoloration.

\subsection{The Usage of Synthetic Ultramarine}

Lapis lazuli (natural) and ultramarine (synthetic) are two types of ultramarine blue pigments used in color painting. It is difficult to distinguish between lapis lazuli and manufactured ultramarine since they have similar chemical compositions and hues. With the advancement of relevant research, several researchers have reviewed ultramarine blue pigment identification technology in painted cultural artifacts and have presented numerous ways to determine whether ultramarine pigment is artificially produced, one of which is Raman spectroscopy[22]. Raman spectroscopy may not only establish whether the sample is lapis lazuli, but also serve as a foundation for determining the origin by detecting the information of related minerals in the sample[23-25]. At the same time, the related Raman data obtained will be reasonably complete owing to the great purity of the synthetic ultramarine material. The bending vibration peak of S3 and the peak of S3 symmetric stretching vibration peak and S2 symmetric stretching vibration peaks are at 260, 548, and $583 \mathrm{~cm}^{-1}$, respectively[26]. There will be frequency doubling peaks, such as $1096 \mathrm{~cm}^{-1} \quad(2 \times 548=1096), \quad 1644 \mathrm{~cm}^{-1}$ $(3 \times 548=1644)$, as well as binding peaks, such as $808 \mathrm{~cm}^{-1}$ $(260+548=808), \quad 1358 \mathrm{~cm}^{-1} \quad(260+(2 \times 548)=1358), \quad$ and $1904 \mathrm{~cm}^{-1} \quad(260+(3 \times 548)=1904)[27]$. The findings from Raman detection of the blue pigment in excellent agreement with the abovementioned peak locations; thus, it is safe to assume that the blue pigment employed in the nunnery's statue painting is synthetic ultramarine $\left(\mathrm{Na}_{6-10} \mathrm{Al}_{6} \mathrm{Si}_{6} \mathrm{O}_{24} \mathrm{~S}_{2-4}\right)$.

\subsection{The Usage of Shellac and Beeswax}

Shellac, also known as lac and paint chips, is a secretion produced by some insects that have been used since antiquity[28]. Across Europe during the 16th century, it was common to dissolve shellac in ethanol solution to produce varnish, which was used to polish furniture and musical instruments[29]. According to some researchers, the use of shellac on bronze swords was discovered in the graves of the Eastern Zhou Dynasty in Shandong, China[30], and shellac was also discovered in the Tang Dynasty color painting of the giant Buddha excavated in Binxian County[31]. It should be notable that it is the first time to report the shellac material was used to form the surface sealing substance in the painted layer of the statue at Zijin Nunnery according to our research results.

As a kind of animal wax, the beeswax composed with 
polymer substance materials was utilized widely in ancient paintings[32]. When it comes to cultural artifacts, it is often used for inlaying and bonding. Beeswax is mentioned in the regulations of the Qing Dynasty craftsmen as being used to connect inlays as one of the primary components of "wax glue"[33]. The beeswax was also found in Several inlaid cultural treasures from the Palace Museum and the lacquer in remnants of the Qing Dynasty Qingcheng lamps[34,35]. Up to know, the application of beeswax as binding medium for painted clay statues has been reported limited in corresponding research, the findings of this study expand the materials field of beeswax application in Chinese colorful statues.

\subsection{Correlation Between the Artificial Pigments and the Repainting Time}

In accordance with the records of Taihu Beikao, the redrawing period of the arhat monument in Zijin Nunnery is "between Kangxi and the beginning of the Qing Dynasty"[6,7]. According to the available data, this is the final time the clay statue of the Zijin Nunnery was painted. However, the findings of this study into the painted pigments of the statues in the main hall revealed that several synthetic pigments, such as chrome yellow, emerald green, and ultramarine, were used in the repainting of the figures.

The development of crocoite pigment began with the examination and investigation of crocoite discovered in Siberia. Lead chromate was originally synthesized in 1809 by French scientist L.N. Vauquelin, and commercial manufacturing started in Germany in 1818[36]. A vivid hue with strong covering strength and excellent tinting strength made chrome yellow one of the most popular materials for redrawing contemporary Chinese painted cultural treasures. The pigments of a painted arhat statue at Lingyan temple, Shandong Province, were studied and analyzed by several researchers, who discovered that the arhat statue had been redrawn up to six times, with the orange pigment consisting of a blend of copper chrome yellow and minium[37]. In addition, the mural paints in the Dazhao Sutra corridor in Lhasa, Tibet, were studied and evaluated by other researchers, who discovered that yellow is lead chrome yellow added to minium and orange red is lead chrome yellow added to cinnabar, which suggests that the main Buddha statue of the Sutra corridor was created between the late Qing Dynasty and the 1980s[38].

The color emerald green was initially discovered in the early 1800s. Wilhelm Sattler of Schweinfurt, Germany, was the first to produce emerald green in 1814. In 1822, Braconnot and Liebig published publications revealing the composition of emerald green and a procedure for its manufacture, and it has been extensively produced and used since then[39]. Emerald green became popular in Chinese art in the 1850s and was frequently utilized as a redrawing pigment. Some academics discovered emerald green in the repainting of Qing Dynasty paintings at Datong's Yungang Grottoes[40]. Some researchers looked at 27 green pigments in oil paintings of historic structures from Shanxi and Beijing, 15 of which were emerald green[41]. Due to its high toxicity and the blackening of hydrogen sulfide in the air, the use of emerald green was progressively phased out from the end of the 20th century to the beginning of the 21 st century[42].

Synthetic ultramarine blue refers to the ultramarine blue that has been produced in the West since the 1830s (at the earliest 1828) using industrial methods[43]. In the late Qing Dynasty, it was brought to China from Europe. It was not until 1927 that Chinese scientists Dai Anbang, Ling Dingzhong, and other pioneers began synthesizing ultramarine from native raw ingredients in Sichuan and elsewhere. From the Qing Dynasty through 1940, synthetic ultramarine was imported from overseas for usage in the Dunhuang Grottoes[44]. The blue pigment on the murals of Guandi temple in Zhouzhi, Xi'an, was discovered to be manufactured ultramarine following the investigations and studies of several researchers. Based on other findings and data, to was surmised that the painting was repainted in the seventh year of Guangxu[45].

Lead chrome yellow, emerald green, and artificial ultramarine pigments were introduced into China after 1840, which is in conflict with the record that the arhat statues in Zijin Nunnery were painted at the latest during "the reign of Emperor Kangxi of the Qing Dynasty". In light of the above investigation, it can be concluded that the so-called repainting of the "Kangxi Period of the Qing Dynasty" was actually not the last time the statues of Zijin Nunnery were painted.

\section{Conclusion}

Based on the mutual confirmation of the findings of multiple detecting tools, it was discovered that the red pigment on the arhat statue in Zijin Nunnery is cinnabar, the orange pigment is minium, the yellow pigment is chrome yellow, the green pigments are atacamite and emerald green. The discoloration phenomenon was observed in the green area drawn with emerald green pigments, and the production of discoloration was demonstrated as same as the mimetite compounds. Azurite and synthetic ultramarine examples of blue pigments, hydrocerussite was found on the surficial layer of the bottom white color layer, while calcite was found on the inner of this bottom white layer. The painted clay statue's main body comprises quartz, calcite, gypsum, muscovite, kaolinite, and albite. Several sealing materials were used to create the painted surface of the statue, and shellac was identified as the primary component. Large-scale statues were determined to have been covered with beeswax, which acts as a bonding agent between the fabric on the surface and the paint.

All of the current synthetic pigments used in painted statues, such as chrome yellow, emerald green, and ultramarine, are contemporary. Consequently, it may be concluded that the last time colored statues were painted could not have been earlier than the period when synthetic pigments were first manufactured and employed in China. In conclusion, the results show that the last painting of the arhat statues in Zijin Nunnery occurred much later than the recorded Kangxi period of the Qing Dynasty (1661-1722), and that it must have occurred between 1850 and 1900 - that is, during the Tongzhi and Guangxu periods of the Qing Dynasty.

\section{Acknowledgement}

The author would like to express sincere gratitude towards the colleagues of Dunhuang Academe, Feng Yaqi, Wang Zhuo, 
Shan Zhongwei, Zhu Feiqing, Zhao Jinli, Yin Yaopeng, Zhu Shengyun and Zhan Dunyan for their assistance with the data sorting process, as well as the Wuzhong District Cultural Relics Bureau of Suzhou City and the personnel of the Zijin Nunnery Scenic Spot Management Office for their kind gestures.

This research is supported by the Local Project Guided by the Central Government of Gansu Province (06); Science and Technology Project of Gansu Province (Grant No. 21JR7RA759); Project of the Wuzhong District Cultural Relics Management Committee, Suzhou City, Jiangsu Province (Gan WBSJ2018008)".

\section{References}

[1] A. Galli, M. Gargano, L. Bonizzoni, S. Bruni, M. Martini. "Imaging and spectroscopic data combined to disclose the painting techniques and materials in the fifteenth century Leonardo atelier in Milan," Dyes and Pigments, 187, pp. 109112, 2020.

[2] R. Fontana, "Unveiling the invisible in uffizi gallery's drawing $8 \mathrm{p}$ by leonardo with non-invasive optical techniques," Applied Sciences, 11, pp. 7995, 2021.

[3] M. Saleh, L. Bonizzoni, J. Orsilli, S. Samela, A. Galli, "Application of statistical analyses for lapis lazuli stone provenance determination by XRL and XRF," Microchemical Journal, 154, pp. 104655, 2020.

[4] L. Bonizzoni, M. Gargano, N. Ludwig, M. Martini, A. Galli, "Looking for Common Fingerprints in Leonardo's Pupils Using Nondestructive Pigment Characterization," Appl. Spectrosc, 71, pp. 1915-1926, 2017.

[5] L. Bonizzoni, S. Bruni, A. Galli, M. Gargano, V. Guglielmi, N. Ludwig, L. Lodi, M. Martini, "Non-invasive in situ analytical techniques working in synergy: The application on graduals held in the Certosa di Pavia," Microchem. J, 126, pp. 172-180, 2016.

[6] S. Z. Luo, "The Investigation of Ancient Arhat Statue at Zijin Nunnery in East Dongting Mountain," Cultural Relics, 9, pp. 12-21, 1955.

[7] R. Shang, "Research on Arhat Statues in Baosheng Temple and Zijin Temple of Suzhou," Nanjing Arts Institute (Fine Arts \& Design), 3, pp. 105-110, 2020.

[8] S. Y. Guo, "On the Artistic Styles of Three Color-painted Arhat Statues of the Song Dynasty," Relics and Museolgy, 5, pp.109-112, 2015.

[9] P. Vandenabeele, P. D. Paepe, L. Moens, "Study of the 19th century porcelain cards with direct Raman analysis," J. Raman. Spectrosc, 39, pp. 1099-1103, 2010.

[10] Z. Z. Ma, L. Q. Wang, J. Yan, W. H. Zhou, V. Pitthard, T. Bayerova, G. Krist, "Chromatographic, Microscopic, and Spectroscopic Characterization of a Wooden Architectural Painting from the Summer Palace, Beijing, China," Anal. Lett, 52, pp. 1670-1680, 2019.

[11] E. V. Klyachkovskaya, D. V. Guzatov, N. D. Strekal, S. V. Vaschenko, A. N. Harbachova, M. V. Belkov, S.V. Gaponenko, "S.V. Enhancement of Raman scattering of light by ultramarine microcrystals in presence of silver nanoparticles," J. Raman. Spectrosc, 43(6), pp. 741-744, 2012.
[12] Y. Farag, C. S. Leopold, "Development of shellac-coated sustained release pellet formulations," Eur. J. Pharm. Sci, 42(4), pp. 400-405, 2011.

[13] J. Želinská, I. Kopecká, E. Svobodová, S. Milovská, V. Hurai, "Stratigraphic EM-EDS, XRF, Raman and FT-IR analysis of multilayer paintings from the Main Altar of the St. James Church in Levoča (Slovakia)," J. Cult. Herit, 33, pp. 90-99, 2018.

[14] J. Liu, Q. Zhang, F. Ma, S. F. Zhang, Q. Zhou, A. M. Huang, "Three-step identification of infrared spectra of similar tree species to Pterocarpus santalinus covered with beeswax," J. Mol. Struct, 1218, 128484, 2020.

[15] M. Maia, A. I. Barros, F. M. Nunes, "A novel, direct, reagent-free method for the detection of beeswax adulteration by single-reflection attenuated total reflectance mid-infrared spectroscopy," Talanta, pp. 107, 74-80, 2013.

[16] L. Q. Wang, Y. N. Ma, Y. X. Zhang, X. Zhao, Q. J. He, J. Y. Guo, H. T. Ren, "Pigment Identification of Sleeping Buddha at World Cultural Heritage Dazu Rock Carvings With $\mu$-Raman Spectroscopy and Related Research," Spectrosc. Spect. Anal, 40, pp. 3199-3204, 2020.

[17] R. L. Frost, B. J. Reddy, S. J. Palmer, "The structure of mimetite, arsenian pyromorphite and hedyphane-A near-infrared spectroscopic study," Polyhedron, 27(6), pp. 1747-1753, 2008.

[18] Frost, R.L. Reddy, B.J. Palmer, S.J. "The structure of mimetite, arsenian pyromorphite and hedyphane-A Raman spectroscopic study," Polyhedron, 26(13), pp. 2964-2970, 2007.

[19] Z. M. Li, L. L. Wang, H. L. Chen, Q. L. Ma, "Degradation of emerald green: scientific studies on multi-polychrome Vairocana Statue in Dazu Rock Carvings, Chongqing, China," Herit. Sci, 64, pp. 1-12, 2020.

[20] J. Simoen, S. D. Meyer, F. Vanmeert, N. Keyser, E. Avranovich, G. V. Snickt, A. V. Loon, K. Keune, K. Janssens, "Combined Micro- and Macro scale X-ray powder diffraction mapping of degraded Orpiment paint in a 17th century still life painting by Martinus Nellius,' Herit. Sci, 83, pp. 1-12, 2019

[21] C. L. Gu, L. Q. Hu, X. M. Zhang, X.D. Wang, J. Guo, "Climate change and urbanization in the Yangtze River Delta," Habitat. Int, 35, pp. 544-552, 2011.

[22] L. Y. Liu, B. J. Zhang, "Research of Judging Technique of Ultramarine Pigments Used in Polychrome Cultural Relics," Herit. Sci, 12, pp. 7-14, 2021.

[23] I. Werf, C. D. Calvano, R. Laviano, A. Simonetti, L. Sabbatini, "2013 MJ Multi-technique chemical characterisation of a 12-13th-century painted Crucifix," Microchem. J, 106, pp. 87-94, 2013.

[24] C. M. Schmidt, M. S. Walton, K. Trentelman, "Characterization of lapis lazuli pigments using a multitechnique analytical approach: implications for identification and geological provenancing," Anal. Chem, 81, pp. 8513-8518, 2009.

[25] M. Veneranda, M. Irazola, A. Pitarch, M. Olivares, A. Iturregui, K. Castro, J. M. Madariaga, "In - situ and laboratory Raman analysis in the field of cultural heritage: the case of a mural painting," J. Raman. Spectrosc, 45, pp. 228-237, 2014. 
[26] A. C. Prieto, O. Martínez, J. Souto, M. Avella, A. Guedes, "Study of a tabernacle with a remarkable architectural structure: In situ examination using Raman spectroscopy," J. Raman. Spectrosc, 44, pp. 1156-1162, 2013.

[27] P. Colomban, "Lapis lazuli as unexpected blue pigment in Iranian Lajvardina ceramics," J. Raman. Spectrosc, 34, pp. 420-423, 2003.

[28] D. Chen, "Chinese Adhesives and Their Application in Remote Ages," China Historical Materials of Science and Technology, 24, pp. 359-365, 2003.

[29] S. Rivers, N. Umney, Conservation of furniture. Routledge, London, UK, 2007.

[30] X. L. Cheng, S. C. Wu, Y. C. Liu, L. Gao, "Initial analysis on the adhesive in a bronze sword unearthed from East Zhou tombs in Zhoujiazhuang (Zhou Family Village), Shandong province," Sciences of Conservation and Archaeology, 2, pp. 34-37,79, 2008.

[31] J. Fan, L. He, "Analysis and Study of the Pigments and Binding Media of the Grand Buddha Grotto Polychromy in Bin County," Dunhuang research, 1996, 47, pp. 140-153+188.

[32] M. Regert, S. Colinart, L. Degrand, O. Decavallas, "Chemical alteration and use of beeswax through time: accelerated ageing tests and analysis of archaeological samples from various environmental contexts," Archaeometry, 43(4), pp. 549-569, 2001.

[33] S. X. Wang, The case of craftsmen in the Qing Dynasty in China(6), Elephant Publishing House, Zhengzhou, China, 2009 pp. 735-738.

[34] Y. J. Kong, H. Luo, Miao, J. M, “A study of preparation and application of traditional rosin-wax adhesive," Sciences of Conservation and Archaeology, 25, pp. 1-8, 2015.

[35] T. Zhang, B.Q. Kang, N. Wang, Y. Zhang, "Research on the Manufacturing Process of Red Lacquer Carving Embroidery Ball Type Qingcheng Lantern," Museum, 28, pp. 128-136, 2021.

[36] C. L. Du, "Re-understanding of Lead Chromate Pigments," China Paint, 27, pp. 14-17, 2012.

[37] C. C. Wang, Z. M. Li, X. Wan, X. N. Wang, Q. L. Ma, "Scientific study of the Song Dynasty polychrome Arhat statues from the Magic Cliff Monastery in Jinan," Sciences of Conservation and Archaeology, 30, pp. 37-47, 2019.

[38] L. L. Wang, Z. M. Li, X.T. Zhang, J. J. Mei, Q. L. Ma, "Studies on wall painting techniques at Jokhang Temple, Lhasa, Tibet, China," Sciences of Conservation and Archaeology, 26, pp. 84-92, 2014.

[39] K. Keune, J. Mass, A. Mehta, C. Jonathan, M. Florian, "Analytical imaging studies of the migration of degraded orpiment, realgar, and emerald green pigments in historic paintings and related conservation issues," Herit. Sci, 4(1), pp. 1-14, 2016.

[40] G. X. Zhou, H. W. Cheng, "Analysis on pigments of ancient murals in Yungang Grottoes," Archaeology, 10, pp. 948-951, 1994.

[41] L. Q. Wang, J. Yan, X. L. Fan, T. Ma, "Spectral Analysis of Green Pigments of Painting and Colored Drawing in Northern Chinese Ancient Architectures," Spectrosc. Spect. Anal, 30, pp. 453-457, 2010.

[42] C. C. Lombardo. Forever Gothic? Analysis and Interpretation of the Interior of the Great North
Bedchamber at Strawberry Hill, Degree of Master of Science, University of Pennsylvania, USA, 2006.

[43] M. González-Cabrera, P. Arjonilla, A. Domínguez-Vidal, M. J. Ayora-Caada, "Natural or synthetic? Simultaneous Raman/luminescence hyperspectral microimaging for the fast distinction of ultramarine pigments," Dyes. Pigments, 178, pp. 108349, 2020.

[44] J. Y. Wang, "Study on Artificial Ultramarine Pigment in Dunhuang Grottoes," Dunhuang Research, 63, pp. 76-81, 2000.

[45] F. Y. Zhao, J. Feng, M. L. Sun, C. Wu, R. Guo, "The Analysis and Study on the Pigments of the Murals of the Guandi Temple at Hujiapu in Zhouzhi, Xi'an," Relics and Museology, 199, pp. 95-100, 2017.

\section{Author Profile}

Qiang Cui (1981-), female, associate researcher, research direction: science of conservation.

Biwen Shui (1986-), female, research assistant, research direction: science of conservation.

Fasi Wu (1983-), female, professor, research direction: cultural heritage conservation.

Qianli Fu (1979-), male, associate researcher, research direction: analysis and research of cultural relics material.

Xia Feng (1978-), male, associate researcher, research direction: cultural heritage conservation. 